\title{
Clinical significance of NT-proBNP levels in Chronic Kidney Disease Patients with or without Heart Failure: An Indian Perspective
}

\author{
Wasiyeeullah Shaikh ${ }^{1}$, Hemant Mehta $\mathbf{J}^{2}$, Charan Reddy $\mathbf{K V}^{3 *}$, Nitin Gokhale $\mathrm{S}^{\mathbf{4}}$ \\ ${ }_{1,2}$ Department of Nephrology, Lilavati Hospital \& Research Centre, Bandra, Mumbai, India. \\ ${ }^{3,4}$ Department of Clinical \& Interventional Cardiology, Lilavati Hospital \& Research Centre, Bandra, Mumbai, India. \\ *Corresponding author: Charan Reddy KV, Department of Clinical \& Interventional Cardiology, Lilavati Hospital \& Research Center, \\ Mumbai, India.
}

Received Date: December 30, 2020; Accepted Date: March 03, 2021; Published Date: March 06, 2021.

Citation: W Shaikh, H Mehta J, C Reddy, NS Gokhale. (2021) Clinical significance of NT-proBNP levels in Chronic Kidney Disease Patients with or without Heart Failure: An Indian Perspective. Journal of Cardiology Research and Reports. 3(1): Doi: 10.31579/2692-9759/012

Copyright: () 2021 Charan Reddy KV. This is an open-access article distributed under the terms of the Creative Commons Attribution License, which permits unrestricted use, distribution, and reproduction in any medium, provided the original author and source are credited.

\section{Abstract}

Objective: N-terminal pro-brain natriuretic peptide (NT-proBNP) levels are extremely useful in detecting heart failure (HF). However, the effects of renal inadequacy on NT-proBNP levels in patients presenting with or without HF remains less clear. We sought to examine the correlation of NT-proBNP levels in all CKD patients and cut-off values of NT pro-BNP level for the diagnosis of $\mathrm{HF}$ in stable CKD patients as well as CKD patients who are on haemodialysis (HD).

Material and Methods: The study comprises 141 CKD patients of both sexes who presented with or without dyspnea to casualty of Lilavati Hospital, Mumbai, India, were prospectively enrolled, and blood samples collected to estimate NT-proBNP level.

Results: NT-proBNP cut-off level of $1850 \mathrm{pg} / \mathrm{mL}$ for stable CKD patients not on dialysis has a sensitivity of $95 \%$ and specificity of $80 \%$. NT-proBNP cut-off level of $8000 \mathrm{pg} / \mathrm{ml}$ for CKD patients on HD has a sensitivity of $87 \%$ and specificity of $79 \%$. NTproBNP cut-off level of $4200 \mathrm{pg} / \mathrm{mL}$ for all CKD patients has a sensitivity of $85 \%$ and specificity of $81 \%$, for diagnosis of HF.

Conclusion: The clinical use of NT-proBNP is a valuable tool for the evaluation of dyspneic patients with suspected HF, irrespective of renal function. We recommend the above NT-proBNP cut-off levels for diagnosing HF patients in the presence of impaired renal function. Evaluation of the correlation between NT-proBNP levels in CKD is important to identify and to design treatment modalities in order to reduce CVD. Hence, NT-proBNP measurement can be a valuable tool for diagnosis and evaluation of dyspneic patients for early initiation of HF treatment.

Key words: natriuretic peptides; NT-proBNP; chronic kidney disease; heart failure; prognosis.

\section{Introduction.}

Chronic kidney disease (CKD) affects $10 \%$ - 20\% of adults and is associated with adverse clinical outcomes, such as progression to endstage renal disease (ESRD), increased risk of cardiovascular diseases (CVD) and death [1]. As per the latest data from Indian registry, the commonest cause of CKD in India is diabetic nephropathy (30.3\%) followed by chronic glomerulonephritis $(15.8 \%)$ and hypertension (HTN) (14.8\%) [2]. Approximately $30 \%$ of patients with diabetes mellitus (DM) have diabetic nephropathy and with the growing number of DM patients and aging population, there can be a parallel increase in the incidence of CKD [3]. Several studies show that patients with CKD also have a higher prevalence of left ventricular (LV) hypertrophy, ischemic heart disease (IHD), cardiac arrhythmias and valvular calcification, leading to heart failure (HF) with a preserved LV ejection fraction (HFpEF), than in the general population [4-7]. This risk increases up to 10 to 100 fold when a patient begins dialysis [8].

Natriuretic peptides (NPs) includes B-type natriuretic peptide (BNP), and
Amino-terminal prohormone of brain natriuretic peptide (NT-proBNP) are well established in the diagnosis of HF and in ruling out non-cardiac dyspnea [9-12]. In recent years, these peptide based tests have become a useful prognostic biomarkers to assess the response to therapeutic interventions in patients with HF. Of these two NPs, the most frequently used in clinical practice is NT-proBNP [13].

NT-proBNP is a 76 amino-acid long peptide, synthesized and secreted by the ventricular myocardium in response to elevated wall tension in the ventricles [14-16]. The upregulated NT-proBNP levels in the circulation can cause CVD [17], left ventricular dysfunction [18], volume overload [19], vasodilatation and renal output of sodium and water to counter the increased fluid volume resulting from decreased kidney function. Despite this risk, consensus on estimating future cardiovascular (CV) risk is poorly defined for patients with CKD due to heterogeneous relationships between increased levels of NT-proBNP and outcomes, at least in part due to its varying thresholds, and different outcomes across studies [20]. In non-CKD patients, the diagnostic power of NT-proBNP was quite 
different among elderly vs. Non-elderly patients in acute dyspnoeic setting [21].

The elevated NT-proBNP concentration in patients with CKD acts as an independent predictor of all-cause death or major adverse cardiac events (MACEs) in CKD stages-1 to 5 [22, 23]. However, most studies evaluating the predictive power of NT-proBNP were conducted in patients with ESRD and on hemodialysis (HD) [22]. The cut-off values to exclude HF are not clearly defined. In addition, NT-proBNP levels need to be interpreted in light of the worsening degree of renal dysfunction. Thus, an optimal cut-off point, even in the presence of impaired renal function, would become a valuable prognostic marker for the diagnosis of dyspneic CKD patients. In the present study, we measured and compared the plasma concentrations of NT-proBNP in all CKD patients with or without $\mathrm{HF}, \mathrm{CKD}$ patients on $\mathrm{HD}$, and stable CKD patients not on $\mathrm{HD}$ with or without HF.

\section{Material and Methods.}

\section{(a).Study subjects.}

This is a prospective observational study, carried out in Lilavati Hospital and Research Centre, a tertiary care hospital in Mumbai, India from September 2016 to September 2017. The study enrolled 141 CKD patients including males and females who presented with or without dyspnea. Patient's demographic information including age, gender, history of DM and HTN were collected through interviewing. Detailed history regarding symptoms at presentation, duration of kidney disease, past history of comorbid illnesses, personal history like smoking, drugs and alcohol consumption, and family details have also been collected.

\section{(b).Methods.}

Two-dimensional echocardiography (2D-ECHO) was performed in all patients using Vivid E9 machine in the cardiology department of Lilavati Hospital by single operator and reported in accordance to the standards outlined by the American Society of Echocardiography [24]. Patients with acute kidney injury, renal transplant recipients, recently admitted for HF within last 30 days and other causes of dyspnea like sepsis, pulmonary embolism, pneumonia, Chronic obstructive pulmonary disease (COPD) and severe anemia were excluded.

The initial diagnosis of suspected HF was done on basis of history, physical examination supplemented with ECG and chest X-ray using the modified Framingham criteria [25]. All the HF patients received cardiology consultation during their hospitalization to further confirm the diagnosis of HF.

\section{Assay of NT-proBNP}

At admission, venous blood $(\sim 5 \mathrm{cc})$ from patients was collected into Ethylene-Diamine-Tetra-Acetic acid (EDTA) coated Vacutainer (Becton Dickinson, NJ, USA). Plasma was separated by centrifugation at $1,000 \times$ $\mathrm{g}$ for 10 minutes at $4^{\circ} \mathrm{C}$ to remove blood clots. Further centrifugation of the plasma was done at $14,000 \times \mathrm{g}$ for 10 minutes at $4^{\circ} \mathrm{C}$ to remove cell debris. The upper plasma was collected, aliquots $(\sim 200 \mu \mathrm{l})$ were prepared, and stored at $-80^{\circ} \mathrm{C}$ or processed immediately for the quantification of NT-proBNP levels using automated electro chemiluminescence immunoassay "ECLIA" protocol (Cobas e411 analyzers, Roche Diagnostics) as suggested by the manufacturers.

In addition to the estimation of complete blood count (CBC) and hemoglobin $(\mathrm{Hb})$ levels, the levels of $\mathrm{Na}, \mathrm{K}, \mathrm{Cl}, \mathrm{HCO} 3, \mathrm{Ca}, \mathrm{PO} 4$, uric acid, protein, albumin, globulin, creatinine and blood urea nitrogen (BUN) levels were determined using standard methods routinely followed in our hospital.

\section{Evaluation of renal function}

We used serum creatinine to estimate the glomerular filtration rate (GFR) according to the 4-variable Modification of Diet in Renal Disease (MDRD) equation reported earlier [26, 27]. Estimated GFR (eGFR) values represented as units of $\mathrm{ml} / \mathrm{min} / 1.73 \mathrm{~m} 2$. We chose a threshold of eGFR $<60 \mathrm{ml} / \mathrm{min} / 1.73 \mathrm{~m} 2$ for $>3$ months to indicate CKD.

\section{Statistical analysis}

Results were analyzed using IBM-SPSS 15.0 statistical software (SPSS Inc., Chicago, IL, USA) and GraphPad Prism 6.0 software packages. Continuous distributed data are expressed as mean \pm standard deviation (SD). Log-transformation was used for NT- proBNP levels to achieve normality in distribution. Spearman's correlation coefficient was used to correlate echocardiographic parameters with NT-proBNP levels. Comparison of means was carried out by Student's unpaired ' $t$ ' test for numerical data. Relationship between renal function expressed as GFR and NT-proBNP was evaluated by Pearson Correlation Coefficient (r). Sensitivity (true positive value i.e reflecting a test's ability to correctly identify subjects who have a condition) and specificity (true negative i.e reflecting a test's ability to correctly identify subjects who do not have a condition) was determined and expressed as percentages [28]. Receiver operating characteristic (ROC) curve analyses was performed for stable CKD and CKD on HD to assess optimal NT-proBNP cut-off values in patients with $\mathrm{HF}$ and without HF. 'P' value of $<0.01$ level was considered statistically significant. (S: Significant; NS=Non-significant; $\mathrm{t}=$ Student's ' $\mathrm{t}$ ' test; $\mathrm{F}=$ Fisher exact probability test value).

\section{Results.}

\section{(1).Characteristics of the study population}

\section{(a).Etiology of study subjects}

Characteristics of study participant are shown in Table 1. The most common cause of CKD in study subjects $(n=141)$ was diabetic kidney disease $(n=85)$ followed by chronic glomerular nephritis $(n=16)$. Other causes included were: hypertensive nephrosclerosis $(n=3)$, autosomal dominant polycystic kidney disease $(n=3)$, cancer treatment induced diarrhea (CTID) $(n=7)$, CKD post-acute kidney injury (AKI) $(n=3)$, cardio-renal syndrome $(n=5)$, light chain deposition disease (LCDD) $(n=1)$, medullary sponge kidney $(n=1)$, analgesic nephropathy $(n=4)$, congenital single kidney $(n=5)$, UTI $(n=2)$ and unknown etiology $(n=6)$.

\begin{tabular}{l|l|l|}
\multicolumn{1}{c|}{ With CHF } & $\begin{array}{l}\text { Without } \\
\text { CHF }\end{array}$ & $\%$ \\
\hline DM & 3 & 2.1 \\
\hline CGN (Chronic glomerular nephritis) & 16 & 11.3 \\
AKI (Acute kidney injury) & 3 & 2.1 \\
CRS (Cardio renal syndrome) & 5 & 3.5 \\
\hline CTID (Chronic tubulointerstitial nephritis) & 7 & 5.0 \\
DKD (Diabetic kidney disease) & 85 & 60.3 \\
\hline HTN (Hypertension) & 3 & 2.1 \\
\hline LCDD (Light chain deposit disease) & 1 & 0.7 \\
\hline MSK (Medullary sponge kidney) & 1 & 0.7 \\
\hline NSAIDS (Analgesic nephropathy) & 4 & 2.8 \\
\hline Single Kidney & 5 & 3.5 \\
\hline UTI (Urinary tract infection) & 2 & 1.4 \\
Unknown & 6 & 4.4 \\
\hline Total & 141 & 100 \\
\hline
\end{tabular}

Table 1: Etiology of CKD in study population

(b).Comparison of age, gender and CKD duration among patients with or without $\mathrm{HF}$

Of the total 141patients, $92(65.2 \%)$ were males and $49(34.8 \%)$ were females. Among $82 \mathrm{HF}$ patients, 55 (67.1\%) were males and $27(32.9 \%)$ were females [Figure 1a). The mean age of patients varies from 27 to 91 
years, with a mean age of $64.10 \mathrm{yrs}$ (range 50-80 yrs). The average age of patients with $\mathrm{HF}(\mathrm{n}=82)$ was $67.38 \pm 11.71 \mathrm{yrs}$ and without $\mathrm{HF}(\mathrm{n}=59)$ was $59.75 \pm 11.81$ yrs.. Among the 59 patients without HF, 37 (62.70\%) were males and $22(37.30 \%)$ were females, this difference in gender was found to be non-significant. Non-significant difference was also observed in the mean duration of CKD in patients with HF (4.07 $\pm 2.85 \mathrm{yrs})$ and without $\mathrm{HF}(4.42 \pm 3.37 \mathrm{yrs})$.

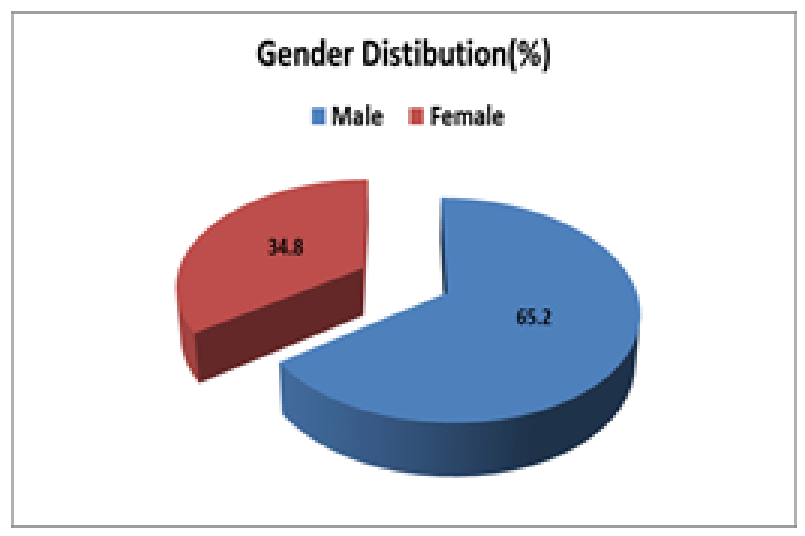

Figure 1a: Distribution of gender in study population.

\section{(c). CKD stage distribution of study population}

CKD stage distribution was performed with an aim to evaluate the association of NT- proBNP levels in CKD patients with and without cardiac dysfunction, and to determine the cut-off values for NT-proBNP levels in stable CKD patients not on HD, and CKD patients on HD versus those presenting with acute breathlessness. Based on CKD stage, 67 (47.50\%) stable CKD patients on HD were in stage 5D and $74(52.40 \%)$ stable CKD patients were not on HD. Among these 74 CKD patients, $31(22.0 \%)$ were in CKD stage-3 (GFR 30-60), 32 (22.70\%) were in CKD stage-4 (GFR 15-30) and $11(7.80 \%)$ were in CKD stage-5 ND (GFR<15) [Figure1b].

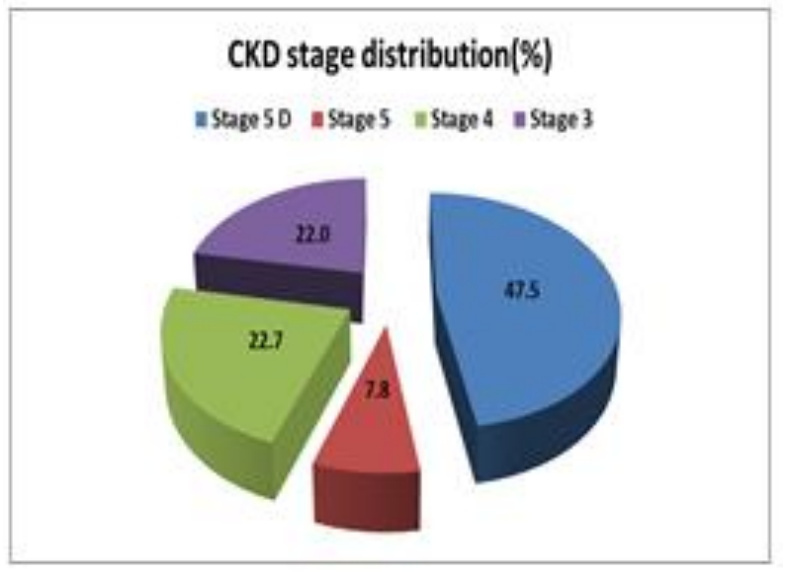

Figure 1b: CKD stage distribution in study population.

\section{Comparison of risk factors of CVD in CKD patients with or without HF}

(A).Comparison of past history (DM, HTN, HF, AF \& MI) among patients with or without $\mathrm{HF}$.

Among the $82 \mathrm{HF}$ patients, $62(75.6 \%)$ had prior history of DM, and of 59 patients without HF $37(62.7 \%)$ had prior history of DM. Among the 82 HF patients, $70(85.4 \%)$ had prior history of HTN, and among 59 patients without HF, $50(84.7 \%)$ had prior history of HTN. These past history were found to be not significant among patients with or without HF. Among the $82 \mathrm{HF}$ patients, 57 (69.5\%) had past history of HF and among 59 patients without HF, $6(10.2 \%)$ had past history of HF. Among the $82 \mathrm{HF}$ patients, $28(34.1 \%)$ had past history of atrial fibrillation (AF) and among 59 patients without HF, 1(1.7\%) had past history of AF. Among the 82 HF patients, $49(59.8 \%)$ had past history of MI, and among 59 patients without HF $5(8.5 \%)$ patients had past history of AF. These three past histories (HF, AF \& MI) were found to be significant $(\mathrm{P}<0.001)$ in patients with $\mathrm{HF}$ as compared to patients without HF [Table-2].

\begin{tabular}{ll|l|c|}
$\begin{array}{l}\text { Past } \\
\text { history }\end{array}$ & With CHF (n=82) & $\begin{array}{l}\text { Without } \\
\text { CHF (n=59) }\end{array}$ & 'P' Value \\
DM & $62(75.6 \%)$ & $37(62.7 \%)$ & NS \\
\hline HTN & $70(85.4 \%)$ & $50(84.7 \%)$ & NS \\
\hline CHF & $57(69.5 \%)$ & $6(10.2 \%)$ & $(\mathrm{P}<0.001)$ \\
AF & $28(34.1 \%)$ & $1(1.7 \%)$ & $(\mathrm{P}<0.001)$ \\
\hline MI & $49(59.8 \%)$ & $5(8.5 \%)$ & $(\mathrm{P}<0.001)$ \\
\hline
\end{tabular}

Table 2: Comparison of past history among patients with or without CHF.

\section{(b).Comparison of NT pro-BNP levels in stable CKD patients with or} without $\mathrm{HF}$

A significant difference in the mean levels of NT-proBNP in stable CKD patients $(\mathrm{n}=43)$ presented with $\mathrm{HF}(15505.2 \pm 15293.40 \mathrm{pg} / \mathrm{mL})$ and those without HF $(\mathrm{n}=31)(1609.70 \pm 3013.40 \mathrm{pg} / \mathrm{mL})$ was recorded. The $\log$ mean values of NT-proBNP in stable CKD patients with $\mathrm{HF}(3.99 \pm 0.45)$ or without HF $(2.79 \pm 0.60)$ were found to be significant between them. The log mean values of NT-proBNP levels in CKD patients on HD with $\mathrm{HF}(4.46 \pm 0.55)$ and without $\mathrm{HF}(3.56 \pm 0.52)$ were found to be significant [Table-3].

\begin{tabular}{|l|l|l|l|}
\hline \multicolumn{1}{|c|}{$\begin{array}{l}\text { CKD } \\
\text { Patients }\end{array}$} & $\begin{array}{l}\text { NT-pro-BNP } \\
\text { levels }\end{array}$ & $\begin{array}{l}\text { Log NT pro- } \\
\text { BNP levels }\end{array}$ & $\begin{array}{l}\text { Level of } \\
\text { significance } \\
\text { ('P' Value })\end{array}$ \\
\hline $\begin{array}{l}\text { Stable CKD } \\
\text { patients with } \\
\text { CHF }\end{array}$ & $\begin{array}{l}15505.2 \\
15293.40\end{array}$ & $3.99 \pm 0.45$ & $(\mathrm{P}<0.001)$ \\
\hline $\begin{array}{l}\text { Stable CKD } \\
\text { patients without } \\
\text { CHF }\end{array}$ & $\begin{array}{l}1609.70 \pm \\
3013.40\end{array}$ & $2.79 \pm 0.60$ & $(\mathrm{P}<0.001)$ \\
\hline $\begin{array}{l}\text { CKD patients on } \\
\text { HD with CHF }\end{array}$ & $\begin{array}{l} \pm 7751.20 \\
\pm 42924.7\end{array}$ & $4.46 \pm 0.55$ & $(\mathrm{P}<0.001)$ \\
\hline $\begin{array}{l}\text { CKD patients on } \\
\text { HD without } \\
\text { CHF }\end{array}$ & $\begin{array}{l}8142.30 \\
\pm 13813.3\end{array}$ & $3.56 \pm 0.52$ & $(\mathrm{P}<0.001)$ \\
\hline
\end{tabular}

Table 3: Comparison of NT-pro-BNP concentrations $(\mathrm{pg} / \mathrm{mL})$ in stable CKD patients with or without CHF.

(c).Comparison of NT pro-BNP levels in CKD patients on HD with or without HF.

A significant difference in the mean levels of NT-proBNP in stable CKD patients on HD presented with HF $(n=39)$ measured to be $47751.20 \pm$ $42924.7 \mathrm{pg} / \mathrm{mL}$. Mean levels of NT-proBNP in CKD patients on HD without HF $(\mathrm{n}=28)$ were estimated to be $8142.30 \pm 13813.3 \mathrm{pg} / \mathrm{mL}$.

Based on the mean NT-proBNP levels, stable CKD patients with and without cardiac dysfunction were further subdivided into four groups. The mean value of NT-proBNP levels in stable CKD patients (not on HD) with GFR <30 $\mathrm{ml} / \mathrm{min}$ was $23581.30 \mathrm{pg} / \mathrm{mL}$, and for patients not on HF and HD with GFR $<30 \mathrm{ml} / \mathrm{min}$ was $4510.60 \mathrm{pg} / \mathrm{mL}$. The mean value of NT-proBNP levels in stable CKD patients (not on HD) with GFR >30 $\mathrm{mL} / \mathrm{min}$ was $14923.10 \mathrm{pg} / \mathrm{mL}$, and for patients not on HF and HD with GFR $>30 \mathrm{ml} / \mathrm{min}$ was $1257.20 \mathrm{pg} / \mathrm{mL}$. These results were statistically significant $(\mathrm{P}<0.001)$ across all groups [Figure 2]. 


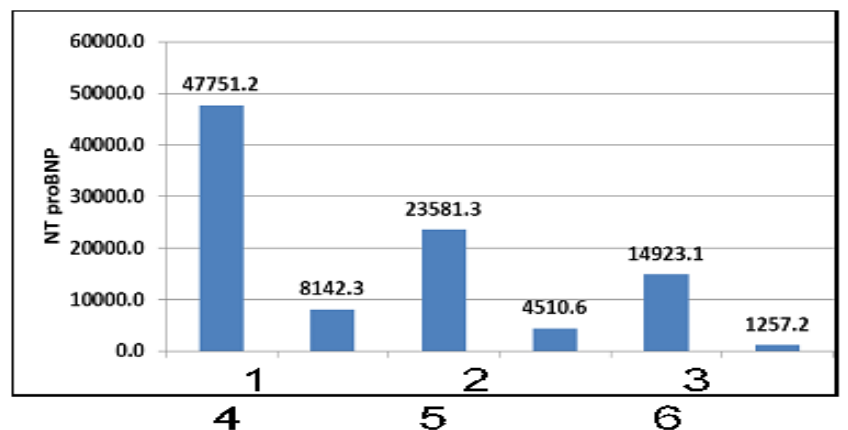

(d).Comparison of serum biochemical parameters and 2D-ECHO results in: (a) stable CKD patients with or without HF and (b) CKD patients on HD with or without HF.

We observed high $(\geq 11.04 \pm 1.85 \mathrm{~g} / \mathrm{dL})$, low $(<10.21 \pm 1.35 \mathrm{~g} / \mathrm{dL})$ levels of hemoglobin $(\mathrm{Hb}$ ), and reduced kidney function (GFR $<$ units $\mathrm{mL} / \mathrm{min} /$ $1.73 \mathrm{~m} 2$ ) were strong predictors of CKD patients. $\mathrm{Hb}$ levels were significantly decreased in stable CKD patients with or without HF. However, no such difference was seen between CKD patients on $\mathrm{HD}$ with or without $\mathrm{HF}$. Also, no change in $\mathrm{CBC}$ count, $\mathrm{Na}, \mathrm{K}, \mathrm{Cl}, \mathrm{HCO} 3, \mathrm{Ca}, \mathrm{PO} 4$, uric acid, protein and albumin levels were observed. There was a significant variation among the 2D-ECHO parameters like regional wall motion abnormality (RWMA), global hypokinesia (GH) and diastolic Figure 2: NT-proBNP levels in stable CKD patients on HD. (1: HD-HF, dysfunction (DD) in both stable CKD patients and CKD patients on HD 2: HD no HF, 3: No HD-HF (GFR <30), 4: No-HD, No-HF (GFR <30), with or without HF [Table-4].

5: No HD-HF (GFR >30 6: No-HD, No-HF (GFR >30)

\begin{tabular}{|l|l|l|l|l|}
\hline Parameter & \multicolumn{2}{|c|}{ Stable CKD patients } & \multicolumn{2}{c|}{ CKD-HD patients } \\
\hline- & With CHF & Without CHF & With CHF & Without CH \\
\hline HB & $10.21 \pm 1.35$ & $11.04 \pm 1.85$ & $10.06 \pm 2.05$ & $10.81 \pm 1.84$ \\
\hline Cr & $2.48 \pm 0.93$ & $3.15 \pm 2.30$ & $6.09 \pm 2.24$ & $6.37 \pm 1.66$ \\
\hline BUN & $31.43 \pm 13.56$ & $35.80 \pm 29.65$ & $47.86 \pm 23.05$ & $53.57 \pm 15.51$ \\
\hline Na & $135.35 \pm 4.54$ & $137.23 \pm 4.51$ & $134.26 \pm 5.03$ & $135.68 \pm 3.47$ \\
\hline K & $4.51 \pm 0.62$ & $4.68 \pm 0.58$ & $4.44 \pm 0.89$ & $4.90 \pm 0.76$ \\
\hline CL & $97.44 \pm 5.41$ & $99.32 \pm 6.45$ & $92.46 \pm 13.78$ & $96.82 \pm 4.97$ \\
\hline HCO3- & $18.38 \pm 4.56$ & $19.69 \pm 2.91$ & $18.38 \pm 4.56$ & $19.69 \pm 2.91$ \\
\hline Ca & $8.75 \pm 0.56$ & $8.76 \pm 0.80$ & $8.50 \pm 0.76$ & $8.61 \pm 0.61$ \\
\hline PO4 & $4.67 \pm 1.06$ & $4.47 \pm 1.32$ & $4.81 \pm 1.99$ & $5.45 \pm 1.25$ \\
\hline Uric acid & $6.50 \pm 1.80$ & $6.34 \pm 1.49$ & $5.98 \pm 2.06$ & $6.38 \pm 1.22$ \\
\hline Protein & $7.00 \pm 0.81$ & $7.26 \pm 0.65$ & $7.26 \pm 0.86$ & $7.21 \pm 0.57$ \\
\hline Albumin & $3.41 \pm 0.40$ & $3.62 \pm 0.41$ & $3.26 \pm 0.49$ & $3.39 \pm 0.46$ \\
\hline Globulin & $3.59 \pm 0.73$ & $3.65 \pm 0.52$ & $3.97 \pm 0.74$ & $3.82 \pm 0.66$ \\
\hline RWMA & $19(44.20 \%)$ & $2(6.5 \%)$ & $8(20.5 \%)$ & $0(0.0 \%)$ \\
\hline GH & $14(32.6 \%)$ & $3(9.7 \%)$ & $24(61.5 \%)$ & $6(21.4 \%)$ \\
\hline DD & $14(32.6 \%)$ & $4(12.9 \%)$ & $15(38.5 \%)$ & $1(3.6 \%)$ \\
\hline LVH & $9(20.9 \%)$ & $6(19.4 \%)$ & $12(30.8 \%)$ & $6(21.4 \%)$ \\
\hline
\end{tabular}

Table 4: Comparison of serum biochemical and 2D- ECHO parameters of stable CKD patients with ( $\mathrm{n}=43$ ) or without CHF ( $\mathrm{n}=31$ ), and CKD patients on HD with $(n=43)$ or without $\mathrm{CHF}(n=31)$. Values are the mean \pm SD.

(e).Association between renal function and NT-proBNP levels in stable CKD patients with or without HF.

Next, the association between renal function (expressed as GFR) and NTproBNP levels in stable CKD patients with or without HF was evaluated using Pearson Correlation Co-efficient (r) analysis. The mean levels of NT-proBNP across the groups showed rising pattern suggesting a rise in mean levels of NT-proBNP with a fall in GFR, albeit this inverse relation was not highly significant $(\mathrm{P}=0.06)$ [Figure 3]. 


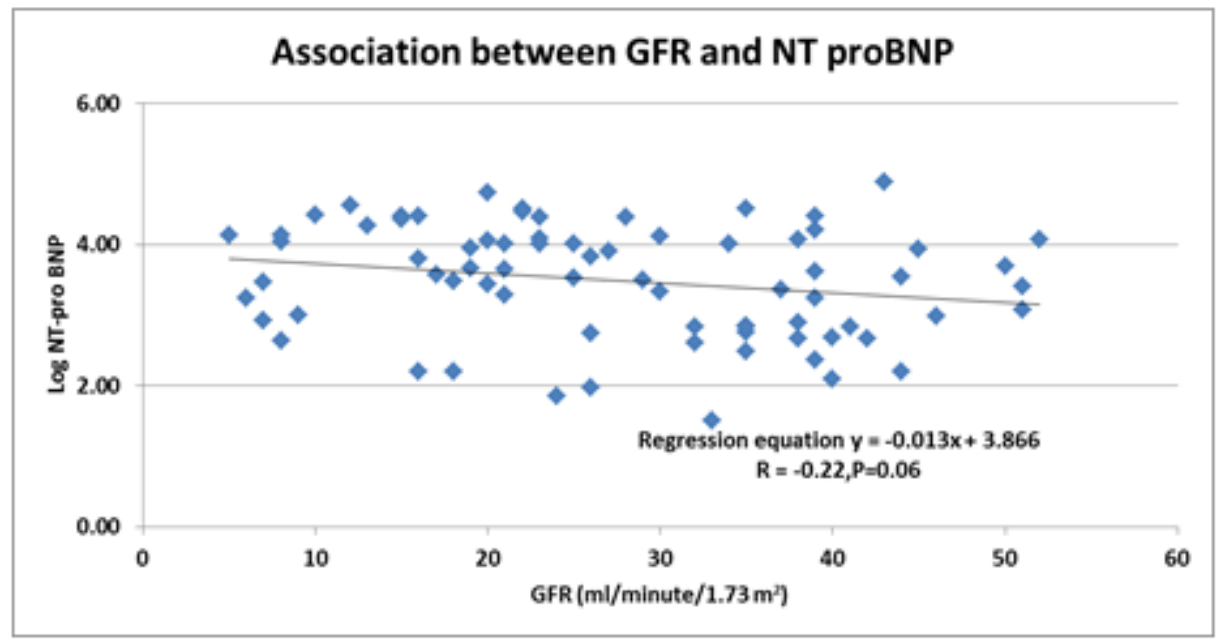

Figure 3: Correlation between GFR and plasma NT-proBNP concentrations was evaluated in CKD patients with or without HF. It was found that with fall in GFR there was a rise in NT pro-BNP concentration, albeit this inverse association was non-significant.

\section{(3). Receiver operating characteristic (ROC) analyses}

(a). CKD patients with or without HF

Next, we used receiver operating characteristic (ROC) analyses to determine optimal NT-proBNP cut-off values for (a) stable CKD patients with or without HF, (b) CKD patients on HD with or without HF and (c) stable CKD patients on HD with or without HF.

To accurate diagnosis of HF, sensitivity (true positive rate) and specificity (true negative rate) were determined. The results revealed that NTproBNP levels were sensitive as well as specific, reflected in the AUC of 0.94 in CKD patients [Figure 4a]. The cut-off value that yielded 97\% sensitivity and $74.0 \%$ specificity was $1200 \mathrm{pg} / \mathrm{mL}$. Increasing the cut point that yielded $95 \%$ specificity and $80.0 \%$ specificity was $1850 \mathrm{pg} / \mathrm{mL}$. The cut-off value that yielded $86 \%$ sensitivity and $90.0 \%$ specificity was $3100 \mathrm{pg} / \mathrm{mL}$.

(b). CKD patients on HD with or without $\mathrm{HF}$
The CKD patients on HD with or without HF, the levels of NT-proBNP were $4000 \mathrm{pg} / \mathrm{mL}$, and is associated with a sensitivity and specificity of $92 \%$ and $75 \%$ respectively. Increasing the cut-off values of NT pro-BNP level to $8000 \mathrm{pg} / \mathrm{mL}$ the sensitivity was reduced to $87 \%$, however specificity increased to $79 \%$. These results indicated that NT-proBNP levels were both sensitive and specific, reflected in the AUC of 0.89 [Figure 4b].

\section{(c). Stable CKD patients on HD with or without HF}

In stable CKD patients, the levels of NT-proBNP were $3100 \mathrm{pg} / \mathrm{mL}$, and is associated with the sensitivity of $91 \%$ and specificity of $74 \%$. Increasing the cut-off NT pro-BNP levels to $4200 \mathrm{pg} / \mathrm{mL}$ reduces the sensitivity to $85 \%$, but increases specificity to $81 \%$. At NT-proBNP levels of $6500 \mathrm{pg} / \mathrm{mL}$, the sensitivity reduced to $79 \%$ and specificity to $86 \%$. These results indicated that NT-proBNP levels were both sensitive and specific, reflected in the AUC of 0.89 [Figure 4c].
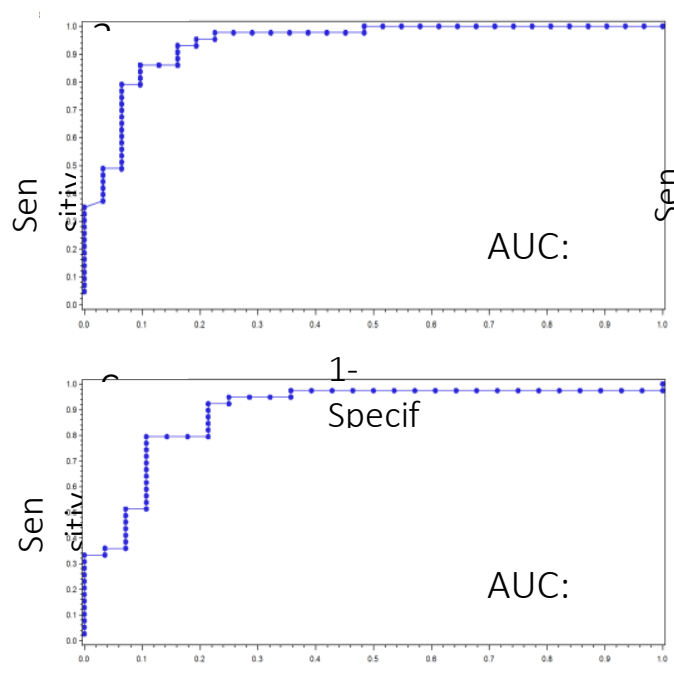

1-

Specif

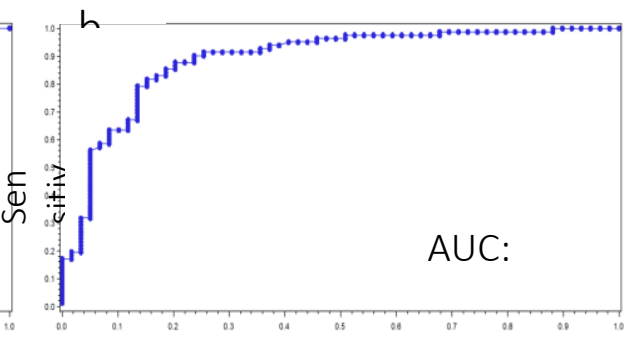

$1-$

Specif

Figure 4a: ROC curves to compare the performance of NT-proBNP for the diagnosis of HF in all CKD patients (a), CKD patients on HD (b) and stable CKD patients not on HD (c). 


\section{Discussion}

CKD can cause HF and vice-versa [29], which indicates that the heart and renal functions are closely interlinked. Cardio-renal syndrome (CRS) is often used to describe this condition and represents an important model for exploring the functional status of heart and kidney. HF can occur due to deranged renal function (patients with $\mathrm{CKD}$ are more likely to have HF) [30].

In clinical practice, serum levels of NT-proBNP are used for the diagnosis and prognosis of HF, but its diagnostic value is limited. HF is a complex clinical syndrome that can result from any structural or functional disorder in the heart that impairs the ability of the ventricles to fill or eject blood leading to raised intracardiac pressures [31]. NT-proBNP levels are increasingly used in the diagnostic evaluation of dyspnoeic patients [32, 9]. NT-proBNP is rapidly released by the ventricles of the heart in response to myocardial stretch. It affects body fluid volume (natriuresis and diuresis) and vascular tone. In the present study, we determined the cut-off values of NT-proBNP in CKD patients present with or without breathlessness for the diagnosis of HF in Indian population. There is no such study on Indian patients, and there is a generalization that NTproBNP is elevated in CKD patients without knowing the cut-off values. In this study, we tried to find out cut point values of NT-pro-BNP in CKD patients presenting with or without dyspnea for an accurate diagnosis of HF.

Significant decrease of $\mathrm{Hb}$ levels in stable CKD patients with or without $\mathrm{HF}$ was observed, which suggests increased adverse events in HF. In contrast, no difference was seen between CKD patients on HD with or without HF. The effect of CKD on NT-proBNP based HF diagnosis revealed serum biochemical profiles, co-morbid conditions and past history were significantly associated with HF. This can be explained as due to high prevalence of DM $(70.2 \%)$ and HTN $(85.1 \%)$ in our study population as the most common cause of CKD was diabetic kidney disease, and the study included patients with moderate to severe kidney disease as well as those who were on hemodialysis (HD).

The plasma NT-proBNP concentrations were positively related to the age. Gender subgroup analysis revealed that NT-proBNP levels in the female group were higher than that of male group, albeit the difference was not statistically significant (Data not shown). The comparison of past history for $\mathrm{AF}$ and $\mathrm{MI}$ was statistically significant in patients with or without $\mathrm{HF}$ $(\mathrm{P}<0.001)$. Further, our data show that there was no significant difference among sex in patients with HF and without HF. These results are in agreement with the data reported by Anwaruddin et al (2006) [33], wherein these authors demonstrated the effects of renal insufficiency on NT-proBNP based HF diagnosis and prognosis.

Takami et al (2004) [34] reported that in 103 non-dialysis dependent patients with renal impairment, without HF had a higher level of serum NTproBNP than patients with HTN and normal renal function. In a prospective study of 1586 patients with acute dyspnea based on NT-proBNP levels revealed that age and past MI were strong independent predictors of HF [32]. Koch et al (2006) [35] reported that NT-proBNP levels decreased with increasing age. In a classical review by Menon et al (2005) [36] described that cardiovascular risk factors in CKD patients associated with traditional (e.g. older age, DM, HTN, smoking, valvular heart disease, dyslipidemia) as well as non-traditional risk factors. The upper limit of normal values is another important consideration of the usefulness of NT-proBNP in the diagnostic evaluation of patients with acute dyspnea [32,9]. The prognosis based on the NT-proBNP levels has not been widely studied in CKD patients, and there is no standard cut points for NT-proBNP to predict adverse events. In asymptomatic CKD patients who did not yet require HD, more than half of the patients had elevated NT-proBNP levels [37].
ROC analysis for all stable CKD patients, CKD patients on HD and stable CKD not on HD with or without HF was carried out to determine the sensitivity and specificity of NT-proBNP for the diagnosis of HF [38]. GFR is generally accepted as the best overall index of kidney function. A metaanalysis published in 2015 summarized the value of NT-proBNP <300 $\mathrm{pg} / \mathrm{ml}$, in the acute setting, showed a very high negative predictive value (NPV) when using low cut-off levels (NT-proBNP $<300 \mathrm{pg} / \mathrm{ml}$ ). These cutoff values, recommended by the European Society of Cardiology (ESC) guidelines are good in excluding diagnosis of HF. They also help to distinguish HF from non-cardiac causes of dyspnoea [39]. ROC curve analysis for discrimination of a GFR of $<30 \mathrm{~mL} / \mathrm{min}$ indentified area under the curve (AUC). For our study, we refer to a GFR $<60 \mathrm{ml} / \mathrm{min} / 1.73 \mathrm{~m} 2$ as decreased GFR and a GFR $<15 \mathrm{ml} / \mathrm{min} / 1.73 \mathrm{~m} 2$ as kidney failure.

In CKD patients, increase in NT-proBNP levels implicated in the compensatory increase in GFR. In these patients, GFR ranged from 15 $\mathrm{ml} / \mathrm{min} / 1.73 \mathrm{~m} 2$ to $24 \mathrm{ml} / \mathrm{min} / 1.73 \mathrm{~m} 2$. NT-proBNP cut point of $1850 \mathrm{pg} / \mathrm{ml}$ for stable CKD patients with GFR $<60 \mathrm{ml} / \mathrm{min} / 1.73 \mathrm{~m} 2$ has a sensitivity of $95 \%$ and specificity of $80 \%$ for the diagnosis of HF (AUC, $0.94 ; 95 \% \mathrm{CI}$, 0.89-0.96, $\mathrm{P}=0.001$ ) in stable CKD patients with or without HF.NTproBNP cut point of $8000 \mathrm{pg} / \mathrm{ml}$ for CKD patients on HD with GFR <60 $\mathrm{ml} / \mathrm{min} / 1.73 \mathrm{~m} 2$ and its corresponding sensitivity and specificity were $87 \%$ and $79 \%$, respectively for the diagnosis of $\mathrm{HF}$ (AUC, 0.89 ; 95\% CI, 0.882-0.906, P=0.001). NT-proBNP cut-off level of $4200 \mathrm{pg} / \mathrm{ml}$ across all CKD patients with GFR $<60 \mathrm{ml} / \mathrm{min} / 1.73 \mathrm{~m} 2$ has a sensitivity of $85 \%$ and specificity of $81 \%$ (AUC, $0.89 ; 95 \%$ CI, 0.896-0.910, $\mathrm{P}=0.001$ ).

CKD patient who have acute breathlessness, but NT-proBNP values are below the above mentioned cut-off values, should prompt the evaluation for other causes of acute dyspnea [9]. Anwaruddin et al (2006) [33] undertook the analysis of participants from ProBNP investigation of dyspnea in the emergency department (PRIDE) study. They reported the value of NTproBNP for the diagnostic evaluation of patients with dyspnea and suspected HF. NT-proBNP values of $450 \mathrm{pg} / \mathrm{ml}$ for patients ages $<50$ years and $900 \mathrm{pg} / \mathrm{ml}$ for patients $>50$ years had a sensitivity of $85 \%$ and a specificity of $88 \%$ for diagnosing acute HF among subjects with GFR >60 $\mathrm{ml} / \mathrm{min} / 1.73 \mathrm{~m} 2$.Using a cut point of $1,200 \mathrm{pg} / \mathrm{ml}$ for subjects with GFR $<60 \mathrm{ml} / \mathrm{min} / 1.73 \mathrm{~m} 2$, they found $89 \%$ sensitivity and $72 \%$ specificity. Fu et al (2013) [40] reported that NT-proBNP predicted all causes of death with cut-off values of $369.50 \mathrm{pg} / \mathrm{ml}$ and $2584.10 \mathrm{pg} / \mathrm{ml}$ in non-CKD and CKD patients respectively.

\section{Summary and Conclusion}

The present study is summarized as follows: (1) the most common cause of CKD in Indian population was diabetic kidney disease followed by chronic glomerulonephritis $(n=16)$, (2) the mean age of patients with HF was higher compared to patients without HF, (3) there was an overall higher prevalence of traditional risk factors in CKD patients, (4) presence of past history of $\mathrm{AF}$ and $\mathrm{MI}$ was found to be associated with an increased risk of $\mathrm{HF},(5)$ anemia was also found to have increased risk for HF in stable CKD patients, (6) the rise in the NT-proBNP levels in CKD patients with worsening of renal function suggests inverse relationship between NTproBNP and GFR, (7) NT-proBNP values are elevated in all CKD stages from 3 to 5-HD, hence mere elevation of NT-proBNP in CKD patients presenting with acute dyspnea should not prompt the diagnosis of HF, (8) NT-proBNP should be measured in all CKD patients presenting with symptoms such as dyspnoea and/or fatigue, as their use facilitates the early diagnosis and help in HF risk stratification, (9). NT-pro BNP has high diagnostic accuracy in discriminating HF from other causes of dyspnoea; the higher the NT-proBNP, the higher the likelihood that dyspnoea is caused by HF, (10). It was found that NT-proBNP cut-off levels for the diagnosis of acute HF in patients presenting with acute dyspnoea are higher compared to those used in the diagnosis of chronic HF in patients with dyspnoea on exertion. Taken together, it may be conclude that, NTproBNP levels can be used not only in the acute setting but also in the 
diagnosis of chronic $\mathrm{HF}$ and even possibly in identification of patients at risk of developing HF.

\section{Limitations of the study}

The present study is not without limitations, which need to be addressed when interpreting results. We understand that this is a single centre study limited by a small number of study population. Larger studies are needed to confirm present findings. In our study population, several factors can affect plasma NT-proBNP levels and patient outcomes, although the results were adjusted for multiple covariates that may be associated with circulating NTproBNP levels and outcomes, there is a possibility of residual confounding factors. In view of cost involved, present study did not include serial evaluation of NT-proBNP levels, which may be useful in detection of failure/timely modification of treatment.

\section{Acknowledgements}

The authors thank all participants for their participation in the study. We also extend our heartfelt gratitude to the staff of Department of Nephrology and Cardiology, at Lilavati hospital and Research Centre, Bandra, Mumbai, India for their expert technical assistance and valued suggestions.

\section{Financial support and sponsorship}

Nil.

\section{Conflict of interest}

The authors declare that they have no competing interests.

\section{References}

1. Segall L, Nistor I, Covic A. (2014) Heart Failure in Patients with Chronic Kidney Disease: A Systematic Integrative Review. BioMed .Research International. Article ID 937398.

2. CKD registry of India: Indian Society of Nephrology.

3. Veerappan I, Abraham G. (2013) Chronic Kidney Disease: Current status, challenges and management in India. Med. Update. 593-597.

4. Rogers FJ, Gundala T, Ramos JE, Serajian A. (2015) Heart Failure with preserved ejection fraction. Am. Osteopath. Assoc. 115 (7): 432-442.

5. Gromadziński L, Januszko-Giergielewicz B, Pruszczyk P. (2014) Hypocalcemia is related to left ventricular diastolic dysfunction in patients with chronic kidney disease. J. Cardiol. 63 (3): 198-204.

6. Vervloet M, Cozzolino M. (2017) vascular calcification in chronic kidney disease: different bricks in the wall? Kidney Int .91:808.

7. Bonakdar F, Noorshargh P, Hedayati P, Nasri H. (2020) Investigation of factors related to $\mathrm{N}$-terminal pro-B type natriuretic peptide levels in hemodialysis patients; a single center study. J. Nephropharmacol. 9(1): e05.

8. Komorowska-Jagielska K, Heleniak Z, Januszko-Giergielewicz B. et al. (2016) early and late cardiovascular risk in renal transplant recipients - a literature review. Forum Nefrol. 9 (2):99-108.

9. Januzzi JL Jr, Camargo CA, Anwaruddin S. et al. (2005) The Nterminal Pro-BNP Investigation of Dyspnea in the Emergency Department (PRIDE) study. Am. J. Cardiol .95 (8): 948-54.

10. Casals G, Azzalini L, Tomas C. et al. (2012) Admission B-type natriuretic peptide retains prognostic value in patients with acute coronary syndrome and preserved left ventricular ejection fraction. Int. J. Cardiol.158 (3): 459-60.

11. Verschuren F, Bonnet M, Benoit MO. et al. (2013)The prognostic value of pro-B-Type natriuretic peptide in acute pulmonary embolism. Thromb. Res. 131(6):e235-39.

12. García-Alvarez A, Regueiro A, Hernández J. et al. (2014) Additional value of B-type natriuretic peptide on discrimination of patients at risk for mortality after a non-ST-segment elevation acute coronary syndrome. Eur. Heart J. Acute. Cardiovasc. Care. 3(2):
132-40.

13. Akasheva DU, Plokhova EV, Tkacheva ON. Et al. (2015) Agerelated changes of left ventricular diastolic function, NT-proBNP level and their association with leukocyte telomere length. Kardiologiia. 55(5): 59-65.

14. Kellett J. (2006) Prediction of mortality of patients with suspected heart failure by brain natriuretic peptide concentrations $>100 \mathrm{pg} / \mathrm{ml}$ : omparison of a clinical model with brain natriuretic peptide concentrations. Heart. 92 (10):1512-1513.

15. Nadir MA, Witham MD, Szwejkowski BR, Struthers AD. (2011) Meta-analysis of B-type natriuretic peptide's ability to identify stress induced myocardial ischemia. Am. J. Cardiol. 107(5):662667.

16. Niizuma S, Iwanaga Y, Yahata T, Miyazaki S. (2017) Renocardiovascular biomarkers: from the perspective of managing chronic kidney disease and cardiovascular disease. Front. Cardiovasc. Med.4:1-11.

17. Khan IA, Fink J, Nass C. et al. (2006) N-terminal pro-B-type natriuretic peptide and B-type natriuretic peptide for identifying coronary artery disease and left ventricular hypertrophy in ambulatory chronic kidney disease patients. Am. J. Cardiol. 97 (10):1530-1534.

18. Satyan S, Light RP, Agarwal R. (2007) Relationships of N-terminal pro-B-natriuretic peptide and cardiac troponin $\mathrm{T}$ to left ventricular mass and function and mortality in asymptomatic hemodialysis patients. Am. J. Kidney Dis. 50: 1009-1019.

19. Paniagua R, Ventura MDJ, Diaz MA. Et al. (2010) NT-proBNP, fluid volume overload and dialysis modality areindependent predictors of mortality in ESRD patients. Nephrol Dial Transplant. 25: 551-557.

20. Schaub JA, Coca SG, Moledina DG. Et al. (2015) Amino-terminal pro-B-type natriuretic peptide for diagnosis and prognosis in patients with renal dysfunction: a systematic review and metaanalysis. JACC .Heart Fail .3(12):977-989.

21. Januzzi JL, van Kimmenade R, Lainchbury J. et al. (2006) NTproBNP testing for diagnosis and short-term prognosis in acute destabilized heart failure: an international pooled analysis of 1256 patients: the International Collaborative of NT-proBNP Study. Eur. Heart J. 27: 330-337.

22. Locatelli F, Hannedouche T, Martin-Malo A. et al. (2013)The relationship of NT-proBNP and dialysis parameters with outcome of incident haemodialysis patients: Results from the membrane permeability outcome study. Blood Purif. 35 (1-3):216-223.

23. Oh HJ, Lee MJ, Kwon YE. Et al. (2015) which biomarker is the best for predicting mortalityin incident peritoneal dialysis patients: NTproBNP, cardiac TnT, or hsCRP? Medicine (Baltimore). 94 (44):e1636.

24. Schiller NB, Shah PM, Crawford M. Et al. (1989) Recommendations for quantitation of the left ventricle by twodimensional echocardiography. American society of echocardiography committee on standards, subcommittee on quantitation of two-dimensional echocardiograms. J. Am. Soc. Echocardiogr. 1989; 2:358-367.

25. The natural history of congestive heart failure: the Framingham study N. Eng.1 J. Med. (1971) 285 (26):1441-1446.

26. Levey AS, Eckardt KU, Tsukamoto Y. et al. (2005) Definition and Classification of Chronic Kidney Disease: A position statement from kidney disease: Improving Global Outcomes. Kidney Int. 67:2089-2100.

27. K/DOQI. Clinical practice guidelines for chronic kidney disease: evaluation, classification, and stratification. Am. J. Kidney Dis. (2002) 2 (1): 46-47. 
28. Trevethan R. (2017) Sensitivity, specificity, and predictive values: Foundations, Pliabilities, and Pitfalls in Research and Practice. Front. Public. Health .5: 307.

29. Rutherford E, Mark PB. (2017) what happens to the heart in chronic kidney disease. J. R. Coll. Physicians. 47: 76-82.

30. Sarnak MJ. (2014) a patient with heart failure and worsening kidney function. Clin J Am Soc Nephrol. 9(10):1790-1798.

31. Shu Q, Wu L, Zhang R, Zhang Q, Huang J, Meng Y. (2019) Agedependent changes in cardiac performance, motor function, QoL, and mental status in metoprolol-treated chronic heart failure patients. Sci. Rep. 9 (1):453.

32. Maisel AS, Krishnaswamy P, Nowak RM. et al. (2002) Rapid measurement of B-type natriuretic peptide in the emergency diagnosis of heart failure. N. Engl. J. Med. 347 (3):161-167.

33. Anwaruddin S, Lloyd-Jones DM, Baggish A. et al. (2006) Renal Function, Congestive Heart Failure, and Amino-Terminal Pro-Brain Natriuretic Peptide Measurement: Results from the ProBNP Investigation of Dyspnea in the Emergency Department (PRIDE) Study. J. Am. Coll. Cardiol. 47(1):91-97.

34. Takami Y, Horio T, Iwashima Y. et al. (2004) Diagnostic and prognostic value of plasma brain natriuretic peptide in non-dialysisdependent CRF. Am. J. Kidney Dis. 44: 420- 428.
35. Koch AME, Rauh M, Zink S, Singer H. (2006) Decreasing ratio of plasma N-terminal pro-B-type natriuretic peptide and B-type natriuretic peptide according to age. Acta. Paediatr. 95:805-809.

36. Menon V1, Gul A, Sarnak MJ (2005) cardiovascular risk factors in chronic kidney disease. Kidney Int. 68: 1413-1418.

37. deFilippi CR, Fink JC, Nass CM. et al. (2005) N-terminal pro-Btype natriuretic peptide for predicting coronary disease and left ventricular hypertrophy in asymptomatic CKD not requiring dialysis. Am. J. Kidney Dis. 46: 35-44.

38. Lucisano G, Comi N, Pelagi E. et al. (2015) can renal sonography be a reliable diagnostic tool in the assessment of chronic kidney disease? J. Ultrasound Medicine.34 (2): 299-306.

39. Ponikowski P, Voors AA, Anker SD. et al. (2016) ESC guidelines for the diagnosis and treatment of acute and chronic heart failure: the Task Force for the diagnosis and treatment of acute and chronic heart failure of the European Society of Cardiology (ESC) developed with the special contribution of the Heart Failure Association (HFA) of the ESC. Eur. Heart.J. 37:2129-2200.

40. Fu S, Luo L, Ye P. et al. (2013) the ability of NT-proBNP to detect chronic heart failure and predict all-cause mortality is higher in elderly Chinese coronary artery disease patients with chronic kidney disease. Clin. Interv. Aging. 8:409-417. 